\title{
Correction to: Association of metformin treatment with enhanced effect of anti-VEGF agents in diabetic macular edema patients
}

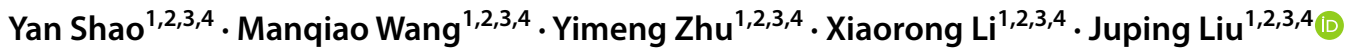

Published online: 3 February 2022

(c) Springer-Verlag Italia S.r.l., part of Springer Nature 2022

\section{Correction to: Acta Diabetologica \\ https://doi.org/10.1007/s00592-021-01833-4}

Authors would like to update Xiaorong Li as co-corresponding author to the original publication.

The original article has been corrected.

Publisher's Note Springer Nature remains neutral with regard to jurisdictional claims in published maps and institutional affiliations.

The original article can be found online at https://doi.org/10.1007/ s00592-021-01833-4.

\section{Xiaorong Li}

xiaorli@163.com

$\triangle$ Juping Liu

tydljp@126.com

1 Laboratory of Retinal Functions and Diseases, Tianjin, China

2 Tianjin Branch of National Clinical Research Center for Ocular Disease, Tianjin, China

3 Eye Institute and School of Optometry, Tianjin, China

4 Tianjin Medical University Eye Hospital, Tianjin, China 